REFEREXCES

AARONSON, D Temporal factors in perception and short-term memory Psychological Bulletin, 1967, 67, $130-144$.

GLANZER, M., GIANUTSOS, R.. \& DUBIN, $S$. The removal of items from short-term storage. Journal of Verbal Learning \& Verbal Behavior, 1969, 8, $435-447$.

LOWE, D. G., \& MERIKLE, P. M. On the disruption of short-term memory by a response prefix. Canadian Journal of Psychology, 1970, 24, 169-177.

MERIKLE, P. M. Unit size and interpolated-task difficulty as determinants of short-term retention.
Joumal of Experimental Psycholog:. $1968,77.370-375$

NEISSER, U. Cognitive psychology. New York: Appleton-Century-Crofts, 1967.

NEISSER, U., HOENIG, Y. J., \& GOLDSTEIN, E. Perceptual organization GOLDSTEIN E. Perceptual the prefix effect. Journal of Verbal Learning \& Verbal Behavior, 1969, 8, 424-429.

POSNER, M, I \& KONICK, A. F. On the role of interference in short-term memory. Journal of Experimental Psychology, 1966, 72, 221-231.

POSNER M I \& ROSSMAN, E. Effect of size and location of informational transforms upon short-term retention. Journal of Experimental Psychology, $1965,70,496-505$

\section{Backward masking of visual targets with internal contours:}

\section{A replication*}

\author{
DUKE ELLIS and WILLIAM N. DEMBER \\ Unviersity of Cincinnati, Cincinnati, Ohio 45221
}

The present results replicate earlier data showing decreased susceptibility to backward masking of disk-shaped targets with increasing numbers of internal black-white segments. Two trends appearing in the earlier study were also investigated: (1) the elevated threshold of a 16-segmented target under a no-masking condition; (2) the facilitation of that target's detectability under a masking condition. Both trends reoccurred in the present data, but only the first was statistically reliable. The results suggest that visual targets with many internal contours in close proximity may generate inhibition as well as excitation, and that for such targets a masking stimulus may serve both to disinhibit and to inhibit target detection.

In a classic study on what is now referred to as backward masking, Nerner (1935) investigated, among several other variables, figural properties of the target stimulus. The finding most pertinent to the present study was that stimuli with internal contours were especially hard to mask, compared with the homogeneous black disk typically employed in Werner's many experiments.

* Supported by Grant No. EY 00481-05 from the National Eye Institute. Thanks to Sue I. Cox for adrice and technical assistance.
To pursue Werner's findings in a more quantitative and objective fashion, Cox \& Dember (1969) compared detectability of the following types of target stimulus: a homogeneous black disk and disks composed of $2,4,8$, or 16 segments half black and half white. Target detectability was measured, using the staircase method and a two-alternative spatial forced-choice indicator, both with and without a masking stimulus. The main variable of interest-number of internal contours-did have a significant effect on target maskability, with differences in target detectability under the nonmasking condition controlled for. That is, the greater the number of internal contours, the less maskable the target.

Further post hoc examination of the data revealed two trends that seemed worth following up. First, the 16-segmented target appeared to be unusually difficult to detect under nonmasking conditions (while at the same time relatively easy to detect when followed by a mask). Secondly, introducing a mask seemed to enhance, rather than decrease, detectability of the 16-segmented target. The two trends together suggested the possibility that mult is egmented targets were self-inhibiting and that for them a mask might, in part, serve a disinhibiting function.

The present experiment was designed to assess the statistical reliability of the above-mentioned trends as well as to replicate the main finding of the Cox and Dember study, that target maskability decreases with increasing amounts of internal contour.

\section{SUBJECTS}

Five female and three male college students, with normal or corrected-to-normal vision, served as paid Ss. All were naive about the purpose of the experiment, and none had had previous experience with backward masking. STMMULI

The present experiment omitted the homogeneous and the 2-segmented disks used by Cox and Dember. Instead, three half-black and half-white disks were employed, those with 4,8 , or 16 alternating black and white segments. Also omitted was the white-ring mask used by Cox and Dember. Only a pair of black rings, horizontally arranged, served as the masking stimulus; a blank gray card was used in the no-mask condition. The same gray provided the background for the target and mask figures.

The diameter of the disks, as well as the inner diameters of the rings, measured $8 \mathrm{~mm}$, subtending $24 \mathrm{~min}$ of arc. The thickness of the walls of the rings subtended $12 \mathrm{~min}$ of arc, and the distance between ring centers subtended 58 min of arc.

\section{APPARATUS AND PROCEDURE}

Since the apparatus used was identical to that of the Cox and Dember study, and the two procedures the same (except for the fact that fewer conditions were run in the present experiment), the following is taken directly from the Cox and Dember paper, modified only to accommodate the change in number of conditions. 
Table 1

Mean Target Duration at Which Detection Occurred

Number of Black and White Target Segments

\begin{tabular}{lccc} 
Testing & \multicolumn{3}{c}{ White } \\
\cline { 2 - 4 } Condition & 4 & 8 & 16 \\
\hline No Mask & 3.31 & 4.36 & 6.47 \\
Mask & 6.46 & 4.86 & 5.48 \\
\hline
\end{tabular}

Stimuli were presented tachistoscopically (Scientific Prototype Model GX). The target stimuli were attached to a plate that could be moved horizontally. The apparatus included adjustable stops so that the positions at which the disk was centered in each of the rings could be marked, and the disk could easily be shifted between these two positions. Viewing was monocular.

The stimuli were presented in the following order: light fixation field, target, mask, light fixation field (target-mask interstimulus interval was $0 \mathrm{msec}$ ). The duration of the target varied, the duration of the mask was $105 \mathrm{msec}$, and the time elapsing between trials was about $10 \mathrm{sec}$. The luminance of all fields was $10 \mathrm{fL}$, with the fixation field present continuously except when the target or mask was presented.

Each $S$ received 10 trials on each of the six stimulus conditions during the 2 days preceding the experiment. The target duration on Practice Day 1 was $20 \mathrm{msec}$, on Day 2, $10 \mathrm{msec}$. On each of the remaining 6 days of the experiment, $\mathrm{S}$ received only one of the six conditions. The order in which the stimuli were presented to the $S$ was random on both practice days and during the actual experiment and was different for each $\mathrm{S}$. On a single trial, the disk was positioned randomly in one of the two rings (or, in the no-mask condition, in one of the two positions in which the disk would be placed if rings were present). On signal from $E$, the $S$ pushed a button initiating the stimulus sequence. The $S$ then indicated, by saying "right" or "left," in which of the two rings the target appeared, guessing if necessary.

On the experimental days, the detection threshold of a disk of a particular target-mask combination was determined by varying target duration. The data were collected using staircase methodology combined with the forced-choice indicator. A staircase series was conducted by presenting the $S$ with a target of a given duration. If $S$ responded correctly on two successive trials, target duration was decreased; if $S$ responded incorrectly, duration was increased on the next stimulus presentation.

An ascending and a descending staircase series were conducted concurrentiy in order to prectide anticipation eflects. Whether a griven trial came from the ascending or descending series was detemined randomly, with each group of 10 trials containing an equal number from each. On each experimental day, a preliminary series of 10 trials was used to determine the range of durations containing the threshold, and the end points of this range were used as starting points of the two staircases. Nine levels of target duration were typically used in the double staircase, with the target durations varying in .5-msec steps.

Thirty-five data points of each staircase were collected, the first five of which allowed the two staircases to approach each other; these were not used in the calculation of the threshold value.

\section{RESULTS AND DISCUSSION}

Thresholds for each condition for each $S$ were calculated according to the procedure outlined in Dixon \& Massey (1969). Mean threshold values are given in Table 1. The data were subjected to a two-way analysis of variance, repeated-measures design. The analysis revealed significant main effects of both target type ( $F=5.95$; $\mathrm{df}=2 / 35 ; \mathrm{p}=.01)$ and masking condition $(F=6.79 ; \quad \mathrm{df}=1 / 35$ $\mathrm{p}=.025$ ).

Successful replication of the major finding of Cox and Dember is indicated in the significant interaction between the target type and masking condition variables $(F=12.53$ $\mathrm{d} f=2 / 35 ; \mathrm{p}=.001)$. Inspection of the data in Table 1 reveals the basis of this highly significant interaction; though threshold increases with increasing number of target segments in the no-mask condition, the reverse is so for the masking condition. That is, as predicted, increasing the number of segments decreases the maskability of the target.

The main purpose of the present experiment was to test the reliability of the two trends noted in the Cox and Dember study: (1) the elevated threshold of the 16-segmented target in the no-mask condition and (2) the decrease in threshold for that target when followed by the masking figure.

A Newman-Keuls post hoc analysis revealed that in the no-mask condition the mean threshold value of the 16-segmented target (6.47) was significantly $(p<.05)$ higher than the means of both the 8-segmented target (4.36) and the 4-segmented target (3.31). Similar analysis showed that the difference in mean threshold of the 16-segmented target under masking (5.48) and no-masking (6.47) conditions, though in the expected direction, failed to reach significance
(12 .05). Thus, on of tho two thends noted by Cox and Dember is clearly confirmed; the other, and perhaps more interesting trend (backward facilitation of multisegmented targets), though again present, is not supported in the statistical analysis. At the least, however, the detection threshold of the 16-segmented target was not increased by the masking stimulus. That this is not an artifact of a possible ceiling effect is demonstrated by a comparison of the threshold value of the 16-segmented target in the no-mask condition of the present experiment (6.47) with that of the homogeneous black disk $(22.12)$ in the Cox and Dember study.

It is our contention that a masking stimulus can have two opposing effects: (1) disinhibition of self-generated target inhibition and (2) inhibition of target excitation. Where these two effects balance, the net result would be no change in target threshold. Where there is little or no self-generated target inhibition, as in homogeneous targets or those with few inner contours, the mask would serve primarily to elevate target threshold. Electrophysiological data of the sort provided by Hubel \& Wiesel (1962) unequivocally support the notion of concurrent inhibitory and excitatory effects produced by visual targets. Psychophysical data reported by Kristofferson (1954) indicate that such inhibitory effects are maximal for targets having overlapping internal contours. We would like to propose that the Cox and Dember results, taken together with those of the present study, are sufficiently compelling to encourage further pursuit of this line of speculation. Finally, we would suggest that models of visual backward masking might profit from attempts to take into account the results of the large number of studies that demonstrate the importance of configurational variables. Models of masking will be inadequate if they are based exclusively on data from experiments in which only temporal and luminance variables are studied.

\section{REFERENCES}

COX, S. I., \& DEMBER, W. N Backward masking of visual targets with internal contours. Psychonomic Science, 1970. 19, 255-256

DIXÓN, J. W., \& MASSEY, F. J. Introduction to statistical analysis. New York: McGraw-Hill, 1969.

HUBEL, D. H. \& WTESEL, T, N. Receptive fields, binocular interaction and functional architecture in the cat's visual cortex. Journal of Physiology, 1962, 160, 106-154.

KRISTOFFERSON, A. B. Foveal intensity discrimination as a function of area and shape. Unpublished doctoral dissertation, University of Michigan, 1954.

WERNER, H. Studies on contour: I. Qualitative analysis. American Journal of Psychology, 1935, 47, 40-64. 